Article

\title{
Iranian Diaspora, Reality Television and Connecting to Homeland
}

\author{
Elham Atashi \\ Justice and Peace Studies, Georgetown University, Washington, DC, 20057 USA; E-Mail: ea543@georgetown.edu
}

Submitted: 29 November 2017 | Accepted: 14 June 2018 | Published: 29 June 2018

\begin{abstract}
Befarmaeed Sham, an Iranian diasporic media production adapted from the original UK reality show "Come Dine with me" features Iranian diaspora of diverse backgrounds as contestants in a cooking reality show. The success of the show has been unprecedented among audiences back home in Iran, reaching millions of households. Using discourse analysis this article examines the potential of reality TV in widening the scope of public sphere and in providing a space for participation and representation. The key practices to illustrate this are ways diaspora position themselves as subjects through discursive practices to express agency in generating, participating and sharing opinions. Casual talk and the entertaining attribute of reality TV focused on the everyday life of ordinary people, constructs a space to normalize audience engagement with what is otherwise, restrictive taboo topics embedded in themes around belonging, homeland, gender, and identity. The article concludes that the broad system of discourse used by diaspora as participants in the reality show constructs a space for representation. It can be considered as a contribution to enhancing the public sphere to not only communicate and connect with their homeland but to express opinions on broader social issues as a practice of civic engagement. This unique adaptation of reality TV is an important aspect of globalization and in using new media to mobilize diaspora in connecting to homeland.
\end{abstract}

\section{Keywords}

diaspora media; homeland; Iranian diaspora; migration; public sphere; reality TV

\section{Issue}

This article is part of the issue "Media and Communication between the Local and the Global", edited by Jessica Gustafsson (Södertörn University, Sweden) and Kinga Polynczuk-Alenius (University of Helsinki, Finland).

(C) 2018 by the author; licensee Cogitatio (Lisbon, Portugal). This article is licensed under a Creative Commons Attribution 4.0 International License (CC BY).

\section{Introduction}

Since the Islamic Revolution in 1979, millions of Iranians have left their homeland for new locations around the globe. The plurality of Iranian diaspora provides a complex trajectory in the function of homeland both as a point of origin for return, as well as an imaginary, left behind. This latter typology reflects on the framework for understanding the interaction of diaspora with their homeland as fluid and dynamic based on the varied experiences of migration (Cohen, 1997; Morley, 2000; Safran, 1991). The approach taken in this paper considers the relationship between diaspora and their homeland as a dialectic process where diaspora see themselves both as members of a nation and as a no place based on the experience of belonging with metaphors of de- and reterritorialization.
Diasporic media, referring broadly to the multiple platforms of communication produced to meet the specific needs of the diasporic community, has always been prominent in sustaining links between Iranian diaspora and their homeland. With direct input and control over programming, diaspora has established and advanced this specific media as an alternative to dominant national media (Panagakos \& Horst, 2006). The varied set of professional and amateur actors involved in diasporic media that deliver and prepare content has diversified the space for communication (Georgiou, 2007). In the past decade, globalization has accelerated and expanded the capacity of diaspora to use TV networks in connecting to the homeland. On-line technologies have also helped to ease access by eliminating state restrictions and allowing programming from diasporic TV networks to reach domestic audiences directly. 
The intersection of the diaspora community with multiple platforms of media has led to what Appadurai describes as "diasporic public spheres", opening a way for participants to "move from shared imagination to collective action" (1996, p. 8). The use of internet technologies has shaped a much-needed space for civic deliberation by offering diaspora a display to communicate diverse opinions on social, economic and political concerns back home (Newland, 2010; Parham, 2005). The dynamic of diaspora using media and making direct connections to domestic audiences is considered by Brinkerhoff (2009) as a significant bottom-up strategy of activism and being influential on politics back home. This strategy has been particularly valuable in providing visibility for disadvantaged groups and marginalized communities that do not have co-operative political ties to their country. The Iranian diaspora illustrates this well as they have traditionally utilized diaspora media to provide audiences back home with alternative information. In this context, diaspora media has advanced an agenda for expression and participation in internal political debates, evading the heavily censored state media (Faris \& Rahimi, 2015). While this has expanded the communicative space for engaging with home, it has also led to state measures to discredit the legitimacy of content. The emphasis on influence and mobilization of home audiences has heightened ideological polarization with tensions over diasporic media often labeled as politically motivated (Michaelsen, 2016).

In the past decade, diasporic media have countered such challenges by doing more to adapt to global media. The popularity of reality TV with its entertainment overtones has opened the boundaries of diaspora media attracting home audiences to what has traditionally been a highly polarized space. The genre of reality TV provides access for viewers into the lifestyle and behavior of ordinary people which can also benefit from this space to advance alternative information and awareness on important social issues (Bignell, 2005). One striking feature is the ability to bypass flow of information from official sources of mass media, and give a voice to ordinary citizens as participants.

This paper contributes to a better understanding of how diaspora is localizing this form of global media as a tool of representation, agency, and connection with homeland? What specific practices are used in the representation of diaspora? How are participants in the reality TV using the interplay of communications in negotiating connections to the homeland and in widening the scope of the public sphere? I use one of the most popular reality TV shows Befarmaeed Sham, translated as "please come to dinner" produced by the diasporic network, Manoto TV. It has been adapted based on the UK cooking show "Come Dine with Me". To highlight its distinctive features, the first section provides a review of global reality TV shows and the impact and connection with local audiences. In developing my argument I draw on this section for better understanding of reality TV's potential as a do- main for an alternative form of engagement with audiences and as a public sphere for expression, representation, and agency. The next section provides an outline for understanding the evolution of Iranian diaspora and the complex relations between this community and diasporic media. This relationship has steadily been influenced by local and global factors that involve incessant adaptation to remain relevant as a medium for communication with the homeland. This is followed by discourse analysis of randomly selected episodes of Befarmaeed Sham to illustrate the multiple modes of communication. The paper concludes that although the reliance on the popularity of reality TV as a new form of media can be understood as specific to Iranian diaspora and as a consequence of socio-political context back home, it can also be viewed in enhancing access to the public sphere. Participation of diaspora in the reality show is argued to be a form of self-determined practice that encourages participatory modes of civic engagement in connecting with homeland.

\section{Reality TV and Localizing the Global}

The globalization of western reality TV and local adaptations by national broadcasting networks has been hugely popular. Edwards (2012) associates this success with new directions in storytelling that involves emotional appeals and direct demand for audiences to invest in television programming. Cast members in reality shows are turned into celebrities with participatory fan culture. Reality shows offer a more engaging experience and the ability for audiences to form a deeper connection to programs and its participants. Skeggs and Wood (2012) focus on the intense connections between audiences and participants that unlike other genre requires continuous visual attention and judgement. Audiences are engaging with text beyond its initial delivery in traditional television (Evans, 2011). For Chalaby $(2003$, p. 457) the genre of reality TV is increasingly part of a new global order of transnational networks. The "Real World" and "Survivor" series are considered to be pioneers of reality TV leading the way for other competition-based shows focused on capturing individual participants. The original British show "Pop Idol" for example and its US version has been adapted in over 40 countries. "Got Talent", a British show, has been adapted for broadcast in 58 countries (Kemp, 2014).

One of the promises of reality TV is the capacity to foster democratic processes with its interactive nature and appeal to the masses. The consistent involvement of wide sectors of society with passionate viewers eager to tune in promotes participation. In countries such as Indonesia and China, for example, reality shows have a huge fan base surpassing demand for traditionally popular soap operas. The popularity divulges a triumph in various cultural contexts that exist in dynamic tension with dominant state power. In authoritarian states, the ethos of democracy and salient role of individuals is em- 
phasized with each contestant in reality TV participating as an ordinary person (Bingchun, 2009). The practice of social action and commitment by audiences to participants in the reality shows is an important function. Across the globe, for example, audiences have been so fervent to vote that they have encountered jammed phone lines, often requiring multiple efforts and hours of alert determination to place their votes (Meizel, 2011). For ordinary participants, there is power in social mobility and inclusion in representation previously accessible to elite class and celebrities (Riegert, 2007). Throughout the Arab world, for example, the reality TV "Star Academy" resembling American Idol had become so popular that restaurants owners complained of being empty in the region during its broadcasts (Miles, 2006).

The contribution of reality TV to participatory politics has been mixed. Some scholars consider the superficial nature of such programming and question the direct influence as leading to social change (Jenkins, 2006; Murphy \& Kraidy, 2003). Some have criticized the adaptation of such programs as an invasion of western mass media and promotion of a particular model of selfrepresentation focused on the individual as a real actor and performer (Morreale, 2005; Murray \& Ouellette, 2004; Windle, 2010). Yet, despite the criticism for cultural relativism, the adaptation of global reality TV shows seems to be obscured by its more important functions in promoting participation as a form of civic engagement. Wu (2014) offers insight on the significant link between one of the most popular reality TV shows, "Super Girl" in China and audiences expressing opinions on the broader social issues which enhanced civic engagement. Furthermore, diaspora and other marginalized communities can count on reality TV's entertaining communication in counterbalancing a more positive portrayal of images and narratives that reinforce negative stereotypes (Grassian, 2013). The "Shah of Sunset", for example, a reality show based on the lives of Iranian diaspora living in Los Angeles, has provided a different perspective exposing millions of viewers to the culture, trials, and antics of the Iranian diaspora. This may impact audiences to probe deeper about the Iranian culture and its people.

Representation of participants from marginalized communities exchanging opinions on taboo topics can trigger communications, national dialogue and public debates that would otherwise remain obscure. Punathambekar (2010) for example writes on the deeply political nature of "Indian Idol" and the relationship between reality TV and public discourse to mobilize support for contestants. Graham and Hajru (2011) consider the significant potential for the opening of communication spaces and leading to larger national debates on significant issues. In the South African version of "Big Brother", participants of mixed race and backgrounds were indirectly tackling the issue of race relations and a history of divisions marked by decades of Apartheid (Mathijs \& Jones, 2004, p. 173). The diversity among participants in a reality TV can intersect dominant social norms by provid- ing a public sphere for interaction among individuals of different backgrounds (Nalin, 2008). In societies with a history of tension and conflict along ethnic and racial lines for example reality TV offers an opportunity to surpass differences. The portrayal of ordinary people, rather than actors with attachment to multiple places and diverse communities widens the grounding and scope of belonging and identity (Georgiou, 2010). These networks also play an essential role in the way diasporic communities are reshaping ways to connect and be part of the global cultural scene. For Iranians in Iran, the ability to receive entertainment in their native language from diaspora communities has completely shifted their viewing experience.

\section{The Emergence of Iranian Diaspora and Media}

Since the revolution in 1979, migration has been a consistent part of life for most Iranians. Understanding the structure of migratory waves is vital to understanding the community of Iranian diaspora particularly when taking into consideration the specific positioning of media to the homeland. The first large exodus took place during the dramatic political upheaval of the Iranian revolution and less than year later the Iran-Iraq war. It involved an abrupt migration of Iranians anticipating political and religious persecution. In this wave, exilic identity was the core factor in establishing diaspora media as a transnational network. The subsequent waves of migration were more diverse including non-political categories such as skilled professionals, working-class population, and economic migrants. This is important to note as the different characteristics of migratory waves altered the objectives and needs for utilizing diasporic media in connecting with the homeland (Darznik, 2008).

Some of the earliest diasporic TV launched by the first wave of Iranian migrants were independent run networks typically with a low budget and a single male host. The content was exclusively partisan framed leaving domestic audiences apprehensive and distrustful (Karim, 2003). There were also issues with limited access to programming often requiring high subscription monthly rates. This led to a linguistically defined and elite audience that relied distinctly on these select media platforms to connect and reaffirm belonging to the homeland (Budarick, 2015). In Los Angeles for example, diaspora TV focused on nostalgia and the desire for home by featuring exiled singers and entertainers symbolic of the old homeland (Ghorashi, 2003). The start of online technologies and the internet permeating inside Iran by the late 1990's had a dramatic impact in the direction of diasporic media. The boom in television programming from US and Europe reaching millions of Iranian viewers directly provided alternatives in media consumption. Content had to appeal to an increasingly sophisticated and tech-savvy domestic audience. As more and more Iranians owned satellite dishes, the number of diaspora television networks expanded. The emergent youth culture 
in Iran had gradually grown to rely on the use of social media for information with an unfettered appetite for entertaining programs (Harrison, 2003). Foreign channels became the main source of media consumption among domestic viewers with over 40 native language channels ranging from melodrama dubbed shows to news and entertainment received via satellite from Turkey and the Middle East. Diaspora TV networks were steadily leading a role as a counter-narrative to state media and influential in politics back home. The Iranian government would often place blame for unrest in local streets and uprising as triggered by diasporic TV networks (Fellers \& Moaveni, 2003). This period marked a transition in diaspora media becoming a significant platform for organizing an otherwise fragmented transnational community. The emergence of an influential diaspora media united Iranian migrants through a shared experience of displacement from home (Naficy, 1993).

The diaspora media network Manoto TV, a family owned television channel represents this transition well by achieving an unprecedented popularity with viewers back home. By opening a space, a void in the area of non-political programming it has captured a yearning among home audiences for entertaining content (Bajoghli, 2018). Launched in 2010 from studios in London, programs range from the Iranian diaspora participating as contestants in game shows, late night talk shows, and reality TV, adapted from global formats. Although viewing the global phenomenon of western style reality shows from a local perspective is not new, its adaptation by diasporic television network has delivered a novel way for representation of diaspora as participants in the context of entertainment with cooking, singing and talent shows. Programs are accessed via satellite and on YouTube with the vast majority of viewership inside Iran (Torbati, 2012).

I focus on this diasporic TV network and the popular reality show, Befarmaeed Sham, translated as "please come to dinner". It is based on the original UK cooking show "Come Dine with me" with the distinct difference of diaspora as contestants in an amateur cooking competition. The social text that surrounds the productions is complex and multi-layered as the camera focuses on the interplay of private and every life of diaspora with the backdrop of the host country where each resides. The next section outlines the analytical framework and the data used in this paper. It is focused on the space provided by reality TV as a public sphere and analysis of three dimensions of discourse based on the nature of communications and interactions that constitute the adaptation and use of this global media format in connecting diaspora to homeland.

\section{Method and Analysis}

\subsection{Framework}

Data collection involved random selection of ten episodes of Befarmaeed Sham from 2010-2016 that were filmed across European cities populated by Iranian diaspora. Episodes were accessed and viewed on Manoto YouTube channel. The format of the show is based on four contestants forming a group that meets for the first time in the first contestant's house and dine in each other's home over a period of a week. Each evening after the three-course dinner, prepared by the host, contestants publicly share and evaluate the host's performance in cooking and hospitality with the winner receiving a small cash prize announced in the fourth and final group dinner. Each group of four contestants totals 4 hours of content featured in single 60-minute episodes. The format and sequence for episodes are based on the same order as the original reality show. However, there are differences as each evening's dinner as the contestant hosting the dinner in the group has a formative role in impelling the direction and temperament of each episode. The identification of each episode in this paper is based on the categorization of the group number, followed by episode number featuring each individual contestant and date of the broadcast. All episodes were transcribed and coded for group and episode numbers, participant's gender, age, occupation, marital status, and place of birth. This detailed biography is provided at the start of each episode by the host narrative that is only presented orally.

The methodological approach in this article is based on Fairclough's $(1992,2003,2010)$ discourse analysis. Discourse is defined as multidirectional interactions and processes producing and interpreting the text, as well as the situational context of its use (Fairclough, 1992, p. 3). This broad approach as based on the dialectical relations between language and other objects, moments and elements in the social world or moments along with internal relations. The dimensions of discourse are made apparent in verbal interactions between participants as well as the functions and context of text and performance by each participant. This framework encompasses description, interpretation, and the explanation of the representation of social world through human action. This also corresponds with Gee's (2005) view that the main function of discourse is to facilitate the performance of social activities. The discursive analysis consists of using three pillars of text, discourse practice and sociocultural practice to outline the connections between processes and relations that may not be visible to the producers or analysts of these texts (Fairclough, 2010, p. 132).

\subsection{Text}

The textual analysis involved the examination of verbal styles used by the narrator and the social actors (the contestants and the audience) to convey traits and connections to the homeland. At the beginning of each show, audiences are provided with a brief self-introduction and biography for each participant that includes name, age, the city of birth, number of years living away from home, and occupation. The opening shot launches straight into connecting with the contestants based primarily on the 
identification with the homeland. The camera rotates rapidly back and forth between images of the host country as the context where each diaspora resides and the biography. It combines the narrative self-introduction by each participant in their work setting or public sites such as a playground, coffee shop or restaurant. This nonverbal backdrop facilitates an understanding of the diasporic context for audiences back in Iran, offering them a glimpse of everyday lives in diasporic spaces.

In the introductory section contestants carefully position their identity first on aspects of their individuality and then identification with the homeland. The descriptive bases for representation emphasize agency in individualism. It places the diaspora as subjects in constructing their biography. The sharing of national identity with information such as the place and location of birth provides access to participants within the boundary of the nation-state. This re-territorialization assures audiences back home of a connection while the de-politicization accentuates the entertainment value of the reality show and upholds confidence. This is important for audiences that are typically distrustful of political motives of diasporic media networks. The number of years living as diaspora is included in the biography. The multiple categories of situating the homeland as the place of birth and a palpable place left behind allow participants to represent their sense of interconnected belonging. These examples illustrate this connection.

Sara is female, 41 years old, from the town of Hamedan, a single mother of 2, accountant, has been living in London for 6 years. (Group 10, Episode G3, 2016)

Arvin is male, 21 years old, from Tehran, a student in pharmacy, has been living in London for 3 years. (Group 10, Episode G1, 2016)

Capturing diaspora as participants in the context of the reality show constructs a space away from the portrayal of Iran as the homeland to focus instead on belonging. Using self-described biographical text achieves a multifaceted mode of belonging with ambivalence and resistance to the politicization of identity. The interplay in the biographical style of communication pivots belonging to multiple places with a transnational orientation. The goal of text illustrates agency to display, communicate and promote an identity that transcends differences to focus on the common and collective experience of diaspora as being away from home. To reflect on representation, the range of participants suggests diversity which encourages audiences of different backgrounds to relate to participants.

\subsection{Discourse Practice}

Discourse practice looks into processes of text production, distribution, and consumption. It examines the production and positioning of text in a certain way among possible alternatives. I examine individual storytelling as a specific mode of communication in an intimate setting that provides a singular space for the participant's narrative to emerge. This mode of communication encourages positive values of "ordinariness, informality, authenticity and sincerity" (Fairclough, 2010, p. 158).

Participants engage in a performative and discreet form of storytelling prior to the arrival of guests. The camera is focused entirely on the participant in their private homes and in the backdrop of family photographs and objects such as a painting hanging in a bedroom or a personal item that the participant considers as being important in their lives. The gaze into the private domestic space and personal objects is an effective visual to display socio-economic backgrounds of the diaspora. The openness to allow the public gaze into domestic spaces such as kitchen, living, and bedroom demonstrates trust and sincerity. The show highlights the interrelations between the home and homeland as two complimentary locations with each participant navigating attachment and dis-attachment to each site. The home as the private space of the contestant is infused into the public domain contributing to the informalization of the contemporary society's discourse (Fairclough, 2010).

As the host begins preparation for the dinner, production is focused on individual storytelling as a prelude to the interactive communication with guests that arrive later. This entire section taking up half of the 60-minute episode is focused on the individual participant with the agency to select topics for communication. The pace of the storytelling is reflective, intimate and slower in comparison to the much more upbeat way participants interact with each other later in the show. While each participant starts preparing the ingredients and narrating the recipe for dinner, cooking which is the main theme of the reality show takes a trivial role as a periphery for individual storytelling. Participants use a self-confessional style of storytelling. Though stories audiences come to understand their experience and to convey a specific perspective on varied topics such as the challenges of forced migration, raising children away from family back home, personal freedom, adapting to foreign language, culture, gender relations, loneliness, economic hardship, and erosion in family life. The camera is focused entirely on the participant using a discursive style that echoes an emotional, therapeutic and more intimate communication. This mode exhorts casual informality but also authenticity.

The interplay of emotions immersed in feelings of sadness, grief, and loss, and then by allotment of an object such as family pictures or personal art, stir sentiments of longing for the homeland. Aslama and Pantti (2006) explain that the explicit focus of using emotions in reality TV is emphasized on establishing effective relationship with viewers. Paradoxical implications and correlations between narratives of individual and emotional pain, sadness, and isolation are allied with separation and loss of homeland. 
I want to share with you this picture of my sister (tears are shed silently as participant continues talking) and reminds me of home. (Group 38, Episode E4, 2011)

I have an extensive collection of Tomato ketchup that I wanted to share with the viewers. The reason for this collection is that it is a memory of my homeland and growing up with my brothers, we always used this sauce, which is why I hold on to this memory by collecting these bottles. (Group 42, Episode E4, 2012)

When I first left my homeland and came here (as a migrant), everything was new. I did not have the support network of my family. I did not think I could make it. I want to reach out to all the women like me, living away from home and tell them, that you will make it but it is very challenging and difficult. (Group 19, Episode E1, 2011)

I view my life as better back when I was in Iran, I hope to return to my homeland and to see my family. (Group 60, Episode E4, 2012)

Next, participants position themselves as selfdetermined social actors. Each participant provides a distinctive narrative on the motivation for taking part in the reality TV show. This is used to demonstrate the discursive nature of agency in connecting to home. For example, some participants explicitly point to diasporic identity as isolating them from networks of family and friends and consider participation in the reality show as an opportunity for visibility and in restoring links to the homeland. This narrative is instrumental in enhancing the connection to audiences back home. The expression of dislocation and the desire to re-connect to home as the motivation for participating in the reality show is an effective engagement strategy. It constructs familiarity and an emotional connection between participants and audiences (Hill, 2017).

My mother asked me to participate in this show because she wanted my relatives and family in Iran to see me (my life. I am participating because I want to connect with them. (Group 43, Episode E1, 2012)

I wanted to show you all [referring to audiences] this painting which means a lot to me. It reminds of my homeland, my town, and my community back home which I miss, and wanted to share it. (Group 44, Episode E1, 2012)

The participant-generated content in the form of individual and unscripted storytelling is empowering. It provides a space for each participant in the reality show, as ordinary people to have a voice and more importantly a public sphere for visibility. The self-selection and varied choice of topics illustrate agency regarding the way each participant opts to engage with viewers. The prac- tice of this type of communication fragments the traditional boundaries between participants and viewers, encouraging a new relationship. The commitment, motivation, and contribution of participants to use the space of the reality show to engage with social issues remind audiences of the significance of civic engagement. Moreover, the space for participation is neutral given the right of everyone including marginalized groups such as youth and women to have representation.

\subsection{Sociocultural Practice}

Once the guests arrive, there is a transition from individual storytelling to interactive communication between participants. Various strategies, choices of content and styles are used to produce and present the discourse. The sociocultural practice provides an interpretation of the construction of social identities and representations of the social world through the text by considering aspects such as the context of the situation, and the wider societal context or context of culture (Fairclough, 2010, p. 95).

Opportunities for interaction in small group settings can lead people of different backgrounds to use the space of entertainment and casual talk to construct opinions and interact with other participants. While communication by participants is positional particularly in discussing taboo social issues, different perspectives are openly shared and confrontation is not emphasized. Participants demonstrate interest and commitment to engage in open discussions. This model of communication is influential in exhorting audiences back home to engage with such issues. The ability to talk freely and interact with people that were unknown to each other previous to the show, promote trust. The opportunity for participants as a group and community to self-regulate communications and interactions in the group fosters values of freedom and individual liberty. In this space, exchanges of narrative appear effortless and without an authority or preferred viewpoint providing participants with a sense of agency and empowerment.

Another fundamental emphasis is the salience of gender relations that is presented with key variable and crucial implications for home audiences. Many of Befarmaeed Sham episodes feature mixed age and gender groups. The prominent display of interactions and narrative schemes disrupt the norms on morality and the boundaries for male-female relationships. The visual framing defies strict state censorship rules regarding women's representation and appearance. The public display of socialization between participants removes barriers for interactions. Men and women of all ages, diverse ethnic, education and class backgrounds mix freely to contest gender relations through the re-appropriation of norms and alternative redefinition of what is available but more importantly, is possible. The representation of this diverse and complex interaction provides audiences with an alternative construct for social relations. The space for expression of appearance and interaction 
is fluid and free from social restrictions and state control. Interactions signify a post-gender community featuring participants that invalidate its significance. Identities constructed around the norms of the state are deterritorialized to produce alternatives. For example, male and female participants openly discuss religion, culture, marriage, sexuality, gender identity and other taboo topics such as divorce. Female participants display and communicate their economic independence while the male single parent participants challenge cultural gender role expectations and take an assertive position in cooking and taking care of children. (Group 37, E1, 2011)

When I was younger, I wanted to be a boy instead of a girl. I first became aware of happiness in being a woman (female) and the possibility of freedom when I migrated from home. Back home, there are many impositions and conditions that harbor fear for being a girl. (Group 10, Episode 3, 2011)

After the guests arrive, participants use the group setting for interactions in the private spaces of their homes. This interactive communication provides a public display of expression on a range of social issues based on the lived reality of everyday life of Iranians back home. They openly express opinions and negotiate positions on restrictive issues such as drinking alcohol.

In some episodes depending on the specific host, a variety of alcohol brands are openly consumed by participants. This practice of agency to break social taboos by drinking alcohol is a striking depiction of resistance and in breaking with norms. Moreover, it is an authentic representation of reality back home that is performed and reinforced by participants. Although alcohol consumption is illegal in Iran and punishable by law, its use is fairly widespread. It is hidden from the public gaze and yet, privately a socially acceptable practice (Momtazi \& Rawson, 2010). Participants express diversity and division in the framing of the issue of alcohol consumption. Connection to the homeland is defined by conflict as much as accord, in diverse ways in which the idea of belonging both outside and inside of homeland may be viewed. At the same time, each division of diversity and expression of opinion is rooted in mutual support and respect. These examples illustrate the use of reality TV's unscripted communication and the space offered by diasporic media as a platform for freedom of expression in exchanges between participants.

I opened and served the champagne. Mohammed shared with us that he did not drink alcohol, I respect his choice, and it does not bother me. (Group 1, Episode G1, 2010)

There was a lot of drinking alcohol in the show and it does not fit so well in our culture as the show is called come to dinner-not come drinking. (Group S10, Episode G3, 2016)
Let's not drink (alcohol) tonight as we have in the other nights (several wine bottles are already placed on the dinner table by the host) with each other. But let's lose ourselves and have fun by smoking. (Group 10, P3, 2011)

The socio-cultural practices of discourse through the interaction and communication between participants provide a sphere for representation of expression. The intensity of interactions between participants in this section of the show is much more developed because of the nature of communications on topics pertinent to social issues back home. The right for freedom of expression from state censors enable Befarmaeed Sham to serve as a global space for discussion on local topics that could never be broadcast on domestic television. The multiple levels of interactions generated by participants and incorporated within the entertainment structure of reality TV serve an important function for explicit form of participatory process. Moreover, such discussions and exchanges in the context of reality TV can engage viewers talking and generating discussions during and after shows. From this perspective, even when interaction is not visual, audiences remain or can be influenced by the content from reality shows (Ayish, 2011, p. 768). For viewers back home, the emergent discourse spawned in reality TV and generated in multiple formats by diaspora as participants can have a vital impact in contributing to alternative information.

\section{Conclusion}

This article has explored the participation of diaspora in reality TV mediated by a diasporic media network. It has provided a better understanding of the way diasporic media have adapted successfully to the current global media environment, to appeal to home audiences that seek entertaining television with cultural resonance. The intricate interactions and different communicative features of this genre facilitate what Fairclough (1992) described as discourse.

The rise in alternative ways that diaspora uses global media to communicate with the local has provided innovative forms of engagement in the public sphere. This suggests the participation of diaspora in reality TV as a way to enhance contributions to civic engagement. The open space for the expression of opinions in what Livingstone and Lunt (1994) highlight is interfacing of many discourses, is part of the political process. Reality TV as a form of media takes on many attributes of globalized culture while constructing a new space for showcasing narrative to disseminate information about matters that are often taboo at home. This unique adaptation of reality TV is an important aspect of globalization and in using new media as a practice to mobilize diaspora that remains otherwise fragmented to cultivate the expression of diverse voices and engage with audiences back home. 
While participants share the individual stories of migration and the impact of physical dislocation from the homeland as a distinctive and deeply personal event, the consequences of this experience has led them to belong to a diaspora, which entails an emotional attachment to a place of origin. In contrast to the individualistic experience of migration, participants collectively share the experience of being diaspora. The action and practice of participation in the reality show have unified and reterritorialized an otherwise fragmented community. It has organized diasporic voices as a network to interact as a community away from the homeland. The diversity in participation and manifold forms of expression in the public sphere has provided the diaspora with an accessible tool for civic engagement. It has contributed to opening the media spaces for participation and representation and expanding the framework of public sphere described by Appadurai (1996). The opportunity for a much broader range of people to participate in the reality show, reflects a vision for a more diverse participation back in the homeland.

The space to incite communications and interactions on taboo social issues has also expanded beyond the territory of the homeland to domestic spaces such as the living room of participants in the reality show as sites where Iranians around the world could explore ideas for the future. These occasions might also help to explain issues that could not be done in the homeland due to restrictions that need to be addressed. In doing so, it can link diaspora perspectives and voices with domestic politics and national debates. This unique diasporic global media adaptation serves as a model for a visible and direct way to represent and interact along the nexus of global to local. It is an important aspect of globalization and in media mobilizing diaspora to reterritorialize home. Interventions aimed at bringing about social and political and economic transformation are often carried out by the government and non-government organizations. In societies which are resilient to external influence and intervention, diaspora can use mediated interactions to exert focused, organized, and powerful influence on the homeland.

\section{Acknowledgments}

The author would like to thank the editors of this issue for their comments on the earlier version of this manuscript.

\section{Conflict of Interests}

The author declares no conflict of interests.

\section{References}

Appadurai, A. (1996). Modernity at large-cultural dimensions of globalization. Minneapolis, Minn: University of Minnesota Press.

Aslama, M., \& Pantti, M. (2006). Talking alone: Reality TV, emotions and authenticity. European Journal of Cul- tural Studies, 9(2), 167-184.

Ayish, M. (2011). Television reality shows in the Arab world. Journalism Studies, 12(6), 768-779.

Bajoghli, N. (2018, January 12). A London television station has convinced Iran the shah was great. Foreign Policy. Retrieved from http://foreignpolicy. com/2018/01/12/a-london-television-station-hasconvinced-iran-the-shah-was-great

Bignell, J. (2005). Big Brother: Reality TV in the twentyfirst century. Basingstoke: Palgrave Macmillan.

Bingchun, M. (2009). Who needs democracy if we can pick our favorite girl? Super girl as media spectacle. Chinese Journal of Communication, 2(3), 257-272.

Brinkerhoff, J. M. (2009). Digital diasporas: Identity and transnational engagement. Cambridge: Cambridge University Press.

Budarick, J. (2015). Belonging-security across borders: News media, migration and the spaces of production. International Journal of Communication, 9(18), 2583-2600.

Chalaby, J. K. (2003). Television for a new global order transnational television networks and the formation of global systems. Gazette, 65(6), 457-472.

Cohen, R. (1997). Global diasporas: An introduction. London: UCL Press.

Darznik, J. (2008). The perils and seductions of home: Return narratives of the Iranian diaspora. Melus, 33(2), 55-71.

Edwards, L. H. (2012). Transmedia storytelling, corporate synergy, and audience expression. Global Media Journal, 12(20), 1-12.

Evans, E. (2011). Transmedia television: Audiences, new media and daily life. New York, NY: Routledge.

Fairclough, N. (1992). Discourse and social change. Cambridge: Polity press.

Fairclough, N. (2003). Analyzing discourse: Textual analysis for social research. London: Routledge.

Fairclough, N. (2010). Critical discourse analysis. The critical study of language. Harlow: Pearson Education Ltd.

Faris, D. M., \& Rahimi, B. (Eds.). (2015). Social media in Iran: Politics and society after 2009. New York, NY: SUNY Press.

Fellers, L., \& Moaveni, A. (2003, June 18). Iranian TV from L.A. is a regime change hotbed. LA Times. Retrieved from http://articles.latimes.com/2003/ jun/18/local/me-irantv18

Georgiou, M. (2007). Transnational crossroads for media and diaspora: Three challenges for research. In O. Bailey, M. Georgiou, \& R. Harindranath (Eds.), Transnational lives and the media (pp. 11-32). New York, NY: Palgrave Macmillan.

Gee, J. P. (2005). An introduction to discourse analysis: Theory and method. New York, NY: Routledge.

Georgiou, M. (2010). Identity, space and the media: Thinking through diaspora. Revue Européenne des Migrations Internationales, 26(1), 17-35.

Ghorashi, H. (2003). Ways to survive, battles to win: Ira- 
nian women exiles in the Netherlands and United States. New York, NY: Nova Science Publishers.

Graham, T., \& Hajru, A. (2011). Reality TV as a trigger of everyday political talk in the net-based public sphere. European Journal of Communication, 26(1), 18-32.

Grassian, D. (2013). Iranian and diasporic literature in the 21st Century: A critical study. London: McFarland and Company.

Harrison, F. (2003, July 10). Iran's frustrated generation. BBC News. Retrieved from http://news. bbc.co.uk/2/hi/middle_east/3053383.stm

Hill, A. (2017). Reality TV engagement: Producer and audience relations for reality talent shows. Media Industries Journal, 4(1), 1-17.

Jenkins, H. (2006). Convergence culture: Where old and new media collide. New York, NY: New York University Press.

Karim, K. H. (Ed.). (2003). The media of diaspora. London and New York: Routledge.

Kemp, S. (2014). Simon Cowell's got talent sets Guinness record for world's most successful TV format, Hollywood Reporter. Retrieved from https:// www.hollywoodreporter.com/news/simon-cowellsgot-talent-sets-694091

Livingstone, S., \& Lunt, P. (1994). The mass media, democracy and the public sphere. In S. Livingstone \& P. Lunt (Eds.), Talk on television: Audience participation and public debate (pp. 9-35). London: Routledge.

Mathijs, E., \& Jones, J. (Eds.). (2004). Big Brother international: Format, critics and publics. London: Wallflower Press.

Meizel, K. (2011). Idolized, music, media and identity in American idol. Bloomington, IN: Indiana University Press.

Michaelsen, M. (2016). Exit and voice in a digital age: Iran's exiled activists and the authoritarian state. Globalizations, 15(2), 248-264.

Miles, H. (2006, February 10). Reality TV rivals divide the Arab world. The Telegraph. Retrieved from https:// www.telegraph.co.uk/news/worldnews/africaandin dianocean/algeria/1510164/Reality-TV-rivals-dividethe-Arab-world.html

Momtazi, S., \& Rawson, R. A. (2010). Substance abuse among Iranian high school students. Current Opinion in Psychiatry, 23(3), 221-226.

Morley, D. (2000). Home territories: Media, mobility, identity. London: Routledge.
Morreale, J. (2005). Reality TV, faking it, and the transformation of personal identity. Comparative Literature and Culture, 7(2), 2-7.

Murphy, P., \& Kraidy, M. (Eds.). (2003). Global media studies: Ethnographic perspectives. London: Routledge.

Murray, S., \& Ouellette, L. (Eds.). (2004). Reality TV, remaking television culture. New York, NY: NYU Press.

Naficy, H. (1993). The making of exile cultures: Iranian television in Los Angeles. Minneapolis, MN: University of Minnesota Press.

Nalin, M. (2008). India on television: How satellite TV has changed the way we think and act. New Delhi: Harper Collins.

Newland, K. (2010). Voice after exit: Diaspora advocacy. Diasporas \& development policy project. Washington, DC: Migration Policy Institute.

Panagakos, A. N., \& Horst, H. A. (2006). Return to cyberia: Technology and the social worlds of transnational migrants. Global Networks: A Journal of Transnational Affairs, 6(2), 109-124.

Parham, A. A. (2005). Internet, place, and public sphere in diaspora communities. Diaspora: A Journal of Transnational Studies, 14(2), 349-380.

Punathambekar, A. (2010). Reality TV and participatory culture in India. Popular Communication, 8(4), 241-255.

Riegert, K. (Ed.). (2007). Politicotainment: Television's take on the real. New York, NY: Peter Lang.

Safran, W. (1991). Diasporas in modern societies: Myths of homeland and return. Diaspora: A Journal of Transnational Studies, 1(1), 83-99.

Skeggs, B., \& Wood, H. (2012). Reacting to reality television: Performance, audience and value. New York, NY: Routledge.

Torbati, Y. (2012, April 18). London TV channel dips a toe into Iran culture war. Reuters. Retrieved from https:// www.reuters.com/article/britain-iran-tv/feature-lon don-tv-channel-dips-a-toe-into-iran-culture-war-idU SL5E8EG11V20120418

Windle, J. (2010). Anyone can make it, but there can only be one winner: Modelling neo-liberal learning and work on reality television. Critical Studies in Education, 51(3), 251-263.

Wu, J. C. (2014). Expanding civic engagement in China: Super Girl and entertainment-based online community. Information, Communication \& Society, 17(1), 105-120.

\section{About the Author}

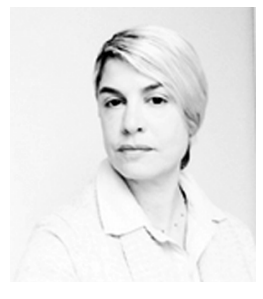

Elham Atashi is Associate Professor of Teaching and Co-Director of the Justice and Peace Studies Program at Georgetown University. Her research and teaching are focused on conflict studies, collective memory, youth, forced migration and using education in conflict transformation processes. 